\title{
Noble gas behaviour in pumice: Implications for volcanic degassing
}

\author{
S. COGLIATI*1, S. C. SHERLOCK ${ }^{1}$, A. M. HALTON ${ }^{1}$ \\ \& T. BARRY ${ }^{2}$ \\ ${ }^{1}$ School of Environment, Earth and Ecosystem Sciences, The \\ Open University, MK7 6AA, Milton Keynes, U.K. \\ (*correspondence: s.cogliati86@gmail.com) \\ ${ }^{2}$ School of Geography, Geology and the Environment, \\ University of Leicester, LE1 7RH, Leicester, U.K.
}

Noble gases (NG) are widely used as tracers of magmatic and volcanic processes. Their abundances and fractionation have been investigated in different volcanic materials, however, studies of NG behaviour in pumices are scarce.

Studying the relationships between eruptive processes, NG content and fractionation in pumices, would contribute to a better understanding of those mechanisms controlling volatiles degassing at the surface during the last stages of magma evolution.

We collected pumices from different portions of the basal fall deposit and upper ignimbrite of the Las Eras Formation, Tenerife, Canary Islands. We systematically compared chemistry, mineral abundance and types and textures of the samples and we studied the NG composition $\left({ }^{4} \mathrm{He},{ }^{36} \mathrm{Ar},{ }^{40} \mathrm{Ar}\right)$ and isotopic ratios $\left({ }^{40} \mathrm{Ar} /{ }^{36} \mathrm{Ar},{ }^{4} \mathrm{He} /{ }^{40} \mathrm{Ar} *\right)$ of pumice glass particles and co-existing alkali feldspars. This approach was designed to investigate those factors controlling the release, fractionation and incorporation of NG in pumice glass and co-existing crystals during different stages of a Plinian eruption taking into account also the possible influence of depositional processes.

Alkali feldspars seem to have recorded the conditions of the magma at depth without being influenced, to a large extent, by syn- and post-eruptive degassing or by weathering. Conversely, we propose that the NG signature of pumice glass particles is the result of multiple processes that interplay and superimpose upon each other and that act, at different timescales, before, during and after the eruption.

The results of our study have implications for the understanding of what information noble gases from pumices can provide on the degassing and evolution of volcanic systems and on the mechanisms and sources of atmospheric contamination in vesiculated pyroclasts. This is particularly relevant for $\mathrm{Ar} / \mathrm{Ar}$ dating, especially when the technique is used for young samples with low radiogenic ${ }^{40} \mathrm{Ar}$ contents, high atmospheric contamination and which can be particularly sensitive to excess ${ }^{40} \mathrm{Ar}$. 